\title{
A Critical Review of Data-Driven Transient Stability Assessment of Power Systems: Principles, Prospects and Challenges
}

\author{
Shitu Zhang ${ }^{1}$, Zhixun Zhu ${ }^{2}$ and Yang $\mathrm{Li}^{1, * \mathbb{D}}$ \\ 1 School of Electrical Engineering, Northeast Electric Power University, Jilin 132012, China; \\ 2202000277@neepu.edu.cn \\ 2 GHN Energy Jilin Jiangnan Thermal Power Co., Ltd., Jilin 132013, China; 12052729@chnenergy.com.cn \\ * Correspondence: liyang@neepu.edu.cn
}

check for

updates

Citation: Zhang, S.; Zhu, Z.; Li, Y. A Critical Review of Data-Driven

Transient Stability Assessment of Power Systems: Principles, Prospects and Challenges. Energies 2021, 14 , 7238. https://doi.org/10.3390/ en14217238

Academic Editors: Pierluigi Siano,

Hassan Haes Alhelou and

Amer Al-Hinai

Received: 25 August 2021

Accepted: 1 November 2021

Published: 2 November 2021

Publisher's Note: MDPI stays neutral with regard to jurisdictional claims in published maps and institutional affiliations.

Copyright: (c) 2021 by the authors. Licensee MDPI, Basel, Switzerland. This article is an open access article distributed under the terms and conditions of the Creative Commons Attribution (CC BY) license (https:// creativecommons.org/licenses/by/ $4.0 /)$.

\begin{abstract}
Transient stability assessment (TSA) has always been a fundamental means for ensuring the secure and stable operation of power systems. Due to the integration of new elements such as power electronics, electric vehicles and renewable power generations, dynamic characteristics of power systems are becoming more and more complex, which makes TSA an increasingly urgent task. Since traditional time-domain simulations and direct method cannot meet the actual operation requirements of power systems, data-driven TSA has attracted growing attention from both academia and industry. This paper makes a comprehensive review from the following four aspects: feature extraction and selection, model construction, online learning and rule extraction; and then, summarizes the challenges and prospects for future research; finally, draws the conclusions of this review. This review will be beneficial for relevant researchers to better understand the research status, key technologies, and existing challenges in the field.
\end{abstract}

Keywords: transient stability assessment; power systems; data-driven approach; feature extraction and selection; model construction; review

\section{Introduction}

Transient stability assessment (TSA) is a fundamental means for ensuring the secure and stable operation of power systems. Transient stability of power systems refers to the ability of each generator in the system to maintain synchronous operation after a large disturbance [1]. With the increasing penetration of new elements such as power electronics, electric vehicles, and renewable power generations, dynamic characteristics of power systems are becoming more and more complex. In this situation, accurate and rapid TSA is increasingly urgent. With the rapid development of artificial intelligence techniques, data-driven TSA approaches became a hot topic in recent years, and a large number of research results were produced. Therefore, it is necessary to make a critical review of existing data-driven TSA approaches so that relevant researchers can better understand the research status, key technologies, and existing challenges in the field.

As summarized in Table 1, existing TSA methods can be roughly divided into three categories: time-domain simulation method [2], direct method [3], and data-driven artificial intelligence (AI) method [4,5]. The basic idea of time-domain simulation methods is to use a numerical integration algorithm to solve the differential-algebraic equations (DAEs) describing the dynamic process of a disturbed power system, and then judge the stability status of the system by the relative angle changes between generator rotors. Due to good model adaptability and reliability, this method was widely used in the electric power industry. Reference [6] proposes the application of the unsymmetric multifrontal method to solve the DAEs encountered in the power system dynamic simulations. Reference [7] proposes a time-domain simulation approach for power system dynamic simulations by using 
unsymmetric multifrontal method. Reference [8] proposes a distributed transient stability simulation algorithm, which has a good, strong scalability. Using the above-mentioned technologies, the existing transient simulation can realize super real-time simulations for large-scale power systems.

Table 1. Principles, advantages, and disadvantages of different TSA methods.

\begin{tabular}{|c|c|c|c|}
\hline Methods & Principles & Advantages & Disadvantages \\
\hline $\begin{array}{l}\text { Time-domain } \\
\text { simulation }\end{array}$ & $\begin{array}{c}\text { Solve } \\
\text { differential-algebraic } \\
\text { equations describing } \\
\text { the dynamic process } \\
\text { of a disturbed } \\
\text { power system }\end{array}$ & $\begin{array}{l}\text { This method has } \\
\text { good scalability with } \\
\text { accurate and } \\
\text { reliable results. }\end{array}$ & $\begin{array}{l}\text { The calculation results } \\
\text { depend on the accuracy } \\
\text { of the system model } \\
\text { and parameters. }\end{array}$ \\
\hline Direct method & $\begin{array}{l}\text { Construct an energy } \\
\text { function to describe } \\
\text { the transient stability } \\
\text { of a power system }\end{array}$ & $\begin{array}{c}\text { This method has fast } \\
\text { calculation speed and } \\
\text { can provide a } \\
\text { stability margin. }\end{array}$ & $\begin{array}{l}\text { The energy function is } \\
\text { difficult to construct, } \\
\text { and the calculation } \\
\text { result is conservative. }\end{array}$ \\
\hline Data-driven TSA & $\begin{array}{l}\text { Judge the stability } \\
\text { status of a disturbed } \\
\text { system using a } \\
\text { trained TSA model }\end{array}$ & $\begin{array}{c}\text { The method has } \\
\text { strong learning ability } \\
\text { and fast } \\
\text { calculation speed. }\end{array}$ & $\begin{array}{l}\text { It acts as a black box } \\
\text { with poor } \\
\text { interpretability and } \\
\text { weak adaptability to } \\
\text { topological changes }\end{array}$ \\
\hline
\end{tabular}

The direct method is a kind of TSA method that uses energy functions constructed by Lyapunov theory [9] to analyze the transient stability of a power system. Reference [10] reveals the role of the Koopman model in power system transient stability assessment. Compared with the time-domain simulation method, this algorithm does not require complex time-domain simulation of the system after a fault, and it can provide a measure of the degree of system stability. References [11,12] propose a single machine equivalent (SIME) method for transient stability assessment. Reference [13] proposes a method for transient stability assessment of a multimachine system by using the extended equal area criterion (EEAC). In addition, phasor measurement units (PMUs) [14] and dynamic state estimator (DSE) [15] can collect online information in real time for TSA.

Unlike the above-mentioned time-domain simulation method and direct method, a data-driven TSA method is model-free, which treats TSA as a pattern recognition problem. In this method, an AI-based assessment model is built to reflect the input power system operational parameters and the transient stability status of the system. This method has the advantages of strong learning ability and fast evaluation speed, which has a good performance in the field of power system transient stability assessment.

To facilitate analysis, the principles, advantages, and disadvantages of different kinds of TSA methods are shown in Table 1.

\section{Principles of Data-Driven Transient Stability Assessment}

As a mode-free method, data-driven TSA regards transient stability assessment as a pattern classification problem, which mainly includes the following aspects: feature extraction and selection, model construction, online learning, and rule extraction. For ease of description, a schematic diagram of data-driven TSA is shown in Figure 1.

In Figure $1, X_{i}(i=1, \ldots, n)$ denotes input feature $i$, and all input features constitute a feature vector as the input of TSA models. A TSA model can learn the mapping relationships between input features and system stability status. After an assessment model is trained, once a new input feature vector is sent to the TSA model, the stability status of the system will be immediately predicted by using the mapping relationship obtained through model training. 


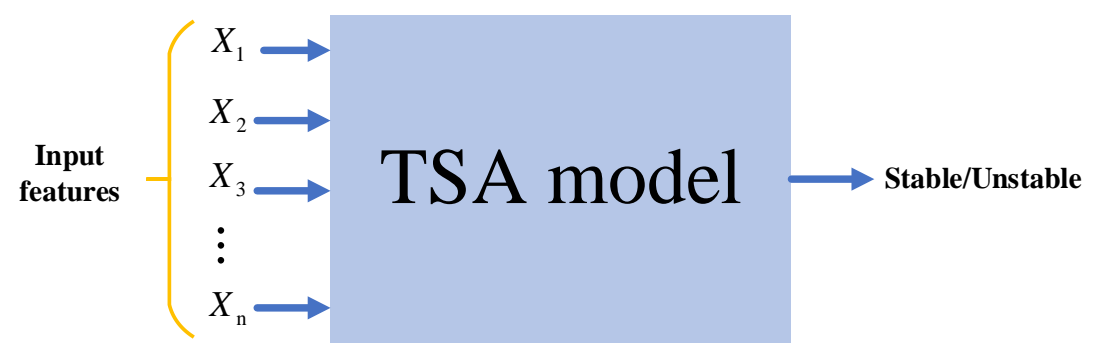

Figure 1. Schematic diagram of data-driven TSA.

\subsection{Feature Extraction and Selection}

Feature extraction and feature selection are two important issues for TSA of power systems. Feature extraction is to extract input features from initial set of measured data, while feature selection refers to the process of choosing a subset of relevant features for use in model construction. Especially, feature selection is a typical combination optimization problem. Compared with that of traditional machine learning algorithms, deep learning can automatically process all features, generate more complex combined features, and eliminate possible omissions in feature extraction algorithms and the subjective factors of researchers.

Based on the structural risk minimization principle, support vector machines (SVMs) can achieve accurate classification in a small sample space. Reference [16] adopts feature selection methods to determine the input variables best suitable for training an ANN-based TSA model. Reference [17] presents an SVM-based two-stage feature selection method: in the first stage, the original feature set is sorted by the SVM recursive feature selection method, and the unimportant features are eliminated to obtain a reduced feature subset; in the second stage, the SVM with radial basis function kernel is used as the classifier to select approximate optimal feature subsets. Reference [18] proposes a TSA method based on enhanced feature selection and least square SVM. Considering the postfault measurement information provided by PMUs, reference [19] proposes a feature selection method based on the improved maximal-relevance and minimal redundancy criterion (mRMR) and SVM for transient stability assessment. In [20], the feature selection algorithm based on random forest and recursive feature elimination is used to extract the key feature subset for TSA.

With the rapid development of AI technology, deep learning was successfully applied to the feature extraction and selection of power system transient stability assessment in recent years. Reference [21] proposes a Fisher linear discriminant function method combined with feature selection technology. Fisher discriminator is used to determine the goodness score of each feature, and then to rank the features according to their scores. Reference [22] proposes a temporal feature selection method for a time adaptive TSA method, which can extract the crucial temporal features by calculating the feature importance. In [23], enhanced feature selection and extraction methods are developed for reducing input features to a probabilistic neural network-based TSA model.

In addition, there are other previous works that develop different feature selection methods for data-driven TSA. Reference [24] proposes an mRMR-based mutual information criterion for feature selection. A TSA approach based on the ensemble of OS-extreme learning machine (EOS-ELM) is put forward by using the binary Jaya algorithm to select the optimal feature subset [25]. Reference [26] presents an artificial neural network (ANN)based TSA approach and points out that proper feature selections make this approach a candidate for addressing a topologically independent assessment process.

\subsection{Model Construction}

For general pattern classification problems, constructing an appropriate assessment model is the key to ensuring a proper balance between complexity and generalization, which can avoid the problem of under-learning or over-learning and improve the model's classification performance. Accordingly, model construction is a critical issue for data- 
driven TSA methods since an appropriate classifier design plays an important role in the performance of the used method.

Existing model construction methods of data-driven TSA mainly include the following categories: ANN, SVM, ensemble learning (EL), and deep learning (DL). These four types of TSA model construction methods are summarized in Table 2.

Table 2. Comparison of different TSA model construction methods.

\begin{tabular}{|c|c|c|c|c|}
\hline Categories & Algorithms & Features & Introduction & Reference \\
\hline \multirow{4}{*}{ ANN } & $\begin{array}{l}\text { Long short-term } \\
\text { memory network } \\
\text { (LSTM) }\end{array}$ & $\begin{array}{l}\text { Voltage phasor and } \\
\text { maximum angle deviation }\end{array}$ & $\begin{array}{l}\text { It proposes a temporal self-adaptive scheme, } \\
\text { it aims to balance the trade-off between } \\
\text { assessment accuracy and response time. }\end{array}$ & [27] \\
\hline & $\begin{array}{l}\text { Spatial-temporal } \\
\text { graph convolutional } \\
\text { network }\end{array}$ & $\begin{array}{l}\text { Voltage magnitude, active } \\
\text { power injection, and reactive } \\
\text { power injection time series }\end{array}$ & $\begin{array}{l}\text { It utilizes graph convolution to integrate } \\
\text { network topology information and adopts } \\
\text { one-dimensional convolution to exploit } \\
\text { temporal information. }\end{array}$ & [28] \\
\hline & $\begin{array}{l}\text { Convolutional } \\
\text { neural network } \\
\quad(\mathrm{CNN})\end{array}$ & Bus voltage & $\begin{array}{l}\text { It can not only assess whether the system } \\
\text { will be stable or unstable, but also predict } \\
\text { the instability mode for the unstable status. }\end{array}$ & [29] \\
\hline & $\begin{array}{l}\text { Recurrent graph } \\
\text { convolution neural } \\
(\text { RGCN) }\end{array}$ & $\begin{array}{l}\text { Bus voltage magnitude, the } \\
\text { bus relative phase and the } \\
\text { rotor speeds of generators }\end{array}$ & $\begin{array}{l}\text { It aggregates both the GCN and the LSTM } \\
\text { unit to form the RGCN. }\end{array}$ & {$[30]$} \\
\hline \multirow{4}{*}{ SVM } & SVM & $\begin{array}{l}\text { Generator rotor angles, } \\
\text { generator speeds, } \\
\text { voltage magnitudes }\end{array}$ & $\begin{array}{l}\text { It can be early predicted based on the } \\
\text { measured postfault values of the generator } \\
\text { voltages, speeds, or rotor angles. }\end{array}$ & {$[31]$} \\
\hline & $\begin{array}{l}\text { Aggressive SVM } \\
\text { (ASVM) and } \\
\text { conservative SVM } \\
\text { (CSVM) }\end{array}$ & $\begin{array}{l}\text { Active power, reactive power, } \\
\text { phase angle of bus voltage, } \\
\text { generator information }\end{array}$ & $\begin{array}{l}\text { It proposes a strategy combining grey } \\
\text { region and two SVMs to deal with the } \\
\text { problems of false alarms and } \\
\text { false dismissals. }\end{array}$ & {$[32]$} \\
\hline & $\begin{array}{l}\text { Core vector machine } \\
(\mathrm{CVM})\end{array}$ & $\begin{array}{l}\text { Load condition, rotor angle, } \\
\text { speed and acceleration }\end{array}$ & $\begin{array}{l}\text { It builds a TSA model based on core } \\
\text { vector machine. }\end{array}$ & {$[33]$} \\
\hline & $\begin{array}{l}\text { Multi-layer SVM } \\
\text { (MLSVM) }\end{array}$ & $\begin{array}{l}\text { Reactive and active power of } \\
\text { generators, bus voltage and } \\
\text { angle, Reactive and active } \\
\text { power of reload }\end{array}$ & $\begin{array}{l}\text { It uses genetic algorithm for a } \\
\text { MLSVM-based TSA model to identify } \\
\text { valued feature subsets with varying } \\
\text { numbers of features. }\end{array}$ & {$[34]$} \\
\hline \multirow{4}{*}{$\begin{array}{l}\text { Ensemble } \\
\text { learning }\end{array}$} & $\begin{array}{l}\text { A denoising stacked } \\
\text { autoencoder and a } \\
\text { voting ensembler }\end{array}$ & Frequency & $\begin{array}{l}\text { It uses cross-entropy to evaluate the fitting } \\
\text { performance of base learners and to set the } \\
\text { weight coefficient in the ensembler. }\end{array}$ & {$[35]$} \\
\hline & $\begin{array}{l}\text { Variational Bayes } \\
\text { multiple kernel } \\
\text { learning }\end{array}$ & $\begin{array}{l}\text { Voltage/current phasor, } \\
\text { active and reactive power, } \\
\text { power factor and } \\
\text { system frequency }\end{array}$ & $\begin{array}{l}\text { It uses the post disturbance PMU data to } \\
\text { predict the system and calculate the stability } \\
\text { margin for a given emergency. }\end{array}$ & {$[36]$} \\
\hline & Mahalanobis Kernel & Network topology & $\begin{array}{l}\text { It makes efficient use of data under different } \\
\text { network topologies, and thus enhances the } \\
\text { estimation accuracy and reduces the need } \\
\text { for training samples. }\end{array}$ & {$[37]$} \\
\hline & $\begin{array}{l}\text { Adaptive ensemble } \\
\text { decision tree (DT) }\end{array}$ & $\begin{array}{l}\text { Voltage magnitudes, } \\
\text { active/reactive power flows } \\
\text { and current flows, voltage } \\
\text { phase angle differences }\end{array}$ & $\begin{array}{c}\text { It proposes an adaptive ensemble DT } \\
\text { learning based TSA approach considering } \\
\text { operating condition variations and } \\
\text { topology changes. }\end{array}$ & [38] \\
\hline
\end{tabular}


Table 2. Cont

\begin{tabular}{|c|c|c|c|c|}
\hline Categories & Algorithms & Features & Introduction & Reference \\
\hline \multirow{3}{*}{$\begin{array}{l}\text { Deep } \\
\text { learning }\end{array}$} & Deep belief network & $\begin{array}{l}\text { Steady-state features, } \\
\text { transient features, } \\
\text { fault removal features }\end{array}$ & $\begin{array}{l}\text { It initializes with unsupervised learning } \\
\text { using unlabeled samples, and then } \\
\text { fine-tune with supervised learning using } \\
\text { labeled samples. }\end{array}$ & [39] \\
\hline & $\begin{array}{c}\text { Stacked } \\
\text { autoencoder (SAE) }\end{array}$ & $\begin{array}{l}\text { Static features, system-level } \\
\text { classification features, } \\
\text { system-level } \\
\text { classification features, }\end{array}$ & $\begin{array}{l}\text { It proposes a SAE based feature reduction } \\
\text { method for TSA. }\end{array}$ & [40] \\
\hline & CNN and LSTM & $\begin{array}{l}\text { Voltage phasor } \\
\text { measurements }\end{array}$ & $\begin{array}{l}\text { It presents a unified deep learning } \\
\text { prediction model for small signal and } \\
\text { transient stability. }\end{array}$ & [41] \\
\hline
\end{tabular}

\subsubsection{ANN-Based TSA}

ANN is a widely used AI algorithm for addressing transient stability assessment problems. In such kind of data-driven TSA method, ANN is utilized to build a TSA model reflecting the mapping relationships between power system operational parameters and the system stability status.

In [26], artificial neural network is used to construct a TSA model for the first time. Reference [27] develops a temporal self-adaptive TSA system by using long short-term memory network (LSTM), which can learn the time dependence of the input temporal sequences. A spatial-temporal graph convolutional network is put forward for TSA of power systems in [28]. Reference [29] proposes a TSA and instability mode prediction model based on convolutional neural network (CNN). A multitask TSA framework is proposed for power systems by using recurrent graph convolutional networks (RGCN) [30].

\subsubsection{SVM-Based TSA}

Compared with that of traditional ANNs, SVM has better generalization ability and stability. Reference [31] introduces a SVM based TSA model and compares it with the common multilayer perceptron models. A real-time TSA approach is presented for power system based on improved SVMs in reference [32]. The improved SVMs include aggressive support vector machine (ASVM) and conservative support vector machine (CSVM). By using big data and the core vector machine (CVM), a TSA method is established in reference [33]. A multilayer SVM (MLSVM) optimized by genetic algorithm (GA) is put forward for transient stability assessment of power systems in reference [34]. The results show that the MLSVM is able to reduce the possibility of misclassification of transient stability assessment.

\subsubsection{Ensemble Learning-Based TSA}

The key idea of ensemble learning is to combine multiple learners into an algorithm model with stronger generalization performance by combining strategies. To analyze transient stability problems, a complete machine learning-based TSA model is proposed for TSA by using a denoising stacked autoencoder and a voting ensemble classifier [35]. A variational Bayes multiple kernel learning (VBpMKL)-based TSA model is built using multi-feature fusion through combining feature spaces corresponding to each feature subset, it can improve the accuracy and reliability of classification [36]. Reference [37] proposes a data-driven TSA model based on Mahalanobis kernel regression and ensemble learning taking into account network topology changes. In [38], an adaptive ensemble learning model based on decision tree (DT) is established to adapt to the changes of system operating conditions and line topology in dynamic security assessment. By this means, the ensemble learning solves the problem of accuracy fluctuations of a single prediction model and greatly improves the reliability of the evaluation results. 


\subsubsection{Deep Learning-Based TSA}

Due to the powerful feature learning and data mining capabilities, deep learning was widely used to build power system stability assessment models in recent years. In [39], a TSA method based on deep belief networks is proposed, and test results show that the presented method performs very well with insufficient training samples or redundant features. Reference [40] puts forward a transient stability assessment method based on deep learning, which constructs three parts of the original feature set and utilizes the stacked autoencoder (SAE) to extract multilevel features. Test results verify that the presented approach is able to reduce the training burden of the assessment model and improve the model's accuracy. Reference [41] proposes a unified deep learning prediction model for analyzing small signal and transient stability of power systems. It uses a CNN-based classifier to determine the transient stability of the system, and then adopts LSTM network to capture low-frequency oscillatory response of a predicted stable system. These studies demonstrate that deep learning has great potential in the field of power system stability assessment [42].

\subsection{Online Learning}

Since that power system is a time-varying system and training samples generated by offline simulations cannot cover all the operating conditions of the system, the TSA model obtained through offline training may not have good applicability in practical applications. For this reason, it is of great significance to study the online learning ability of TSA models.

Research shows that online support vector regression (SVR) is an effective online learning algorithm for super short-term load forecasting of power systems [43]. Furthermore, reference [44] presents a comprehensive transient stability classifier based on improved SVM, which can speed up the training speed by decomposing large-scale training into parallel small-scale training. Reference [45] proposes a TSA method based on the online sequential extreme learning machine (OS-ELM), which can update the assessment model on-line by partial training. A hierarchical deep learning machine (HDLM)-based TSA model is presented to achieve quantitative and qualitative stability prediction in reference [46]. Reference [47] presents a TSA method based on dual cost-sensitivity factors, which can achieve online updating of the model by using incremental learning. In reference [25], an EOS-ELM based TSA model is presented to implement online model updating by using OS-ELM as a weak classifier and the online boosting algorithm as ensemble learning algorithm. In future work, it can use the proposed model as a trigger for wide-area protection. However, it does not take into account the possible PMU failures and communication delays of wide area measurement systems (WAMS) that may occur in real-world power systems, which is shown in Figure 2.

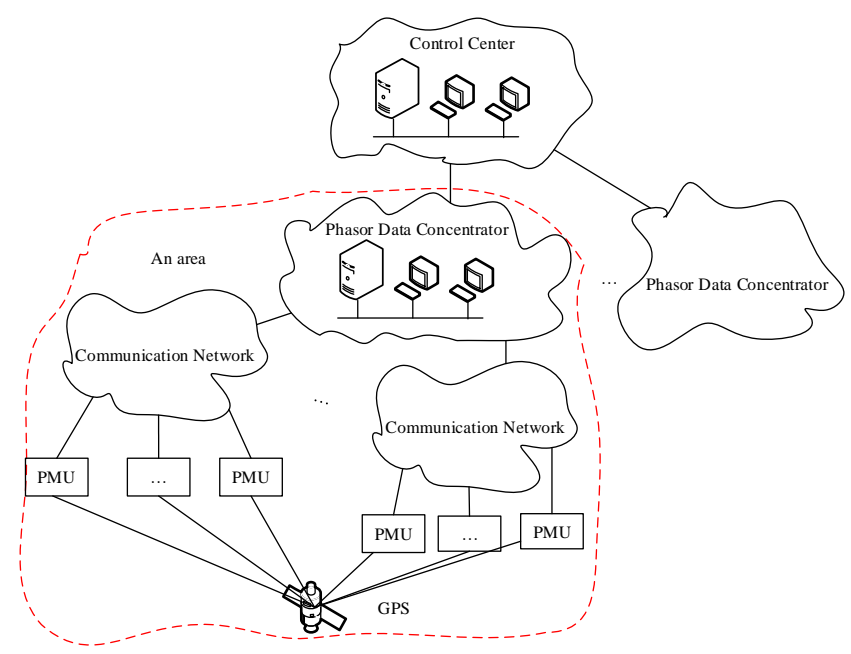

Figure 2. Structure of WAMS. 
As shown in Figure 2, WAMS is a measurement system for a power system including multiple areas, and it typically consists of three components: PMUs, communication system, and control system.

\subsection{Rule Extraction}

The traditional research on transient problems starts from the physical mechanism, and mainly includes the numerical integration method based on mathematical modeling and the direct method of analyzing the energy conversion of the system. Different from time domain simulation or energy function methods, data-driven TSA approaches regard the power system as a "black box" system to fit the relationship between input and output. Rule extraction is an important problem of the "black box" machine learning system, and its purpose is to express the knowledge learned in the learning machine in an easy-tounderstand way.

There are already some previous works in the field of TSA rule extraction. For example, a method for extracting transient stability rules based on linear decision trees is proposed in reference [48], which screens the support samples near the stable boundary as the input samples of the decision tree and reduces the number of samples to obtain safe and stable operation rules based on combined attributes. However, the evaluation results are sensitive to sample composition and the extension ability and robustness of decisionmaking knowledge are poor. Furthermore, reference [49] proposes a method for extracting power grid transient stability rules based on multiattribute decision trees. A decision treebased TSA model is constructed after the discretization of the transient stability margins under some specified faults, then the general rule for evaluating the stability of the system is achieved. However, this reference does not consider economic factors. A method for extracting transient stability assessment rules based on extreme learning machine (ELM) and improved ant-miner (IAM) algorithm is proposed in [50], which has important research value for improving the comprehensibility and interpretability of TSA methods. However, it is necessary to ensure that the generated samples fully reflect the response characteristics of the training model and cover the entire sample space with a uniform distribution. Reference [51] proposes a power system stability assessment and rule extraction approach based on pattern discovery. However, this method only analyzes a single fault and does not extend to cascading faults.

\subsection{Overall Flowchart of Data-Driven TSA}

For ease of presentation, an overall flowchart of a typical data-driven TSA approach is shown in Figure 3.

As shown in Figure 3, the overall process of a typical data-driven TSA can be roughly divided into two stages: offline training and online application. In the stage of offline training, feature extraction and selection are performed to provide appropriate input features, and then an assessment model is constructed to find the right balance between complexity and generalization during the classification process. The assessment model will be trained continuously until its performance meets the expected requirement. In the stage of online application, once an input feature vector obtained from the measured data reaches a trained TSA model, the stability status will be predicted. If the predicted result is unstable, control measures will be initiated at once; otherwise, the evaluation process will continue into the next monitoring cycle. Note that, besides offline data, historical archives of power system operation and new samples generated online can be incorporated into training databases to train/update the assessment model. 


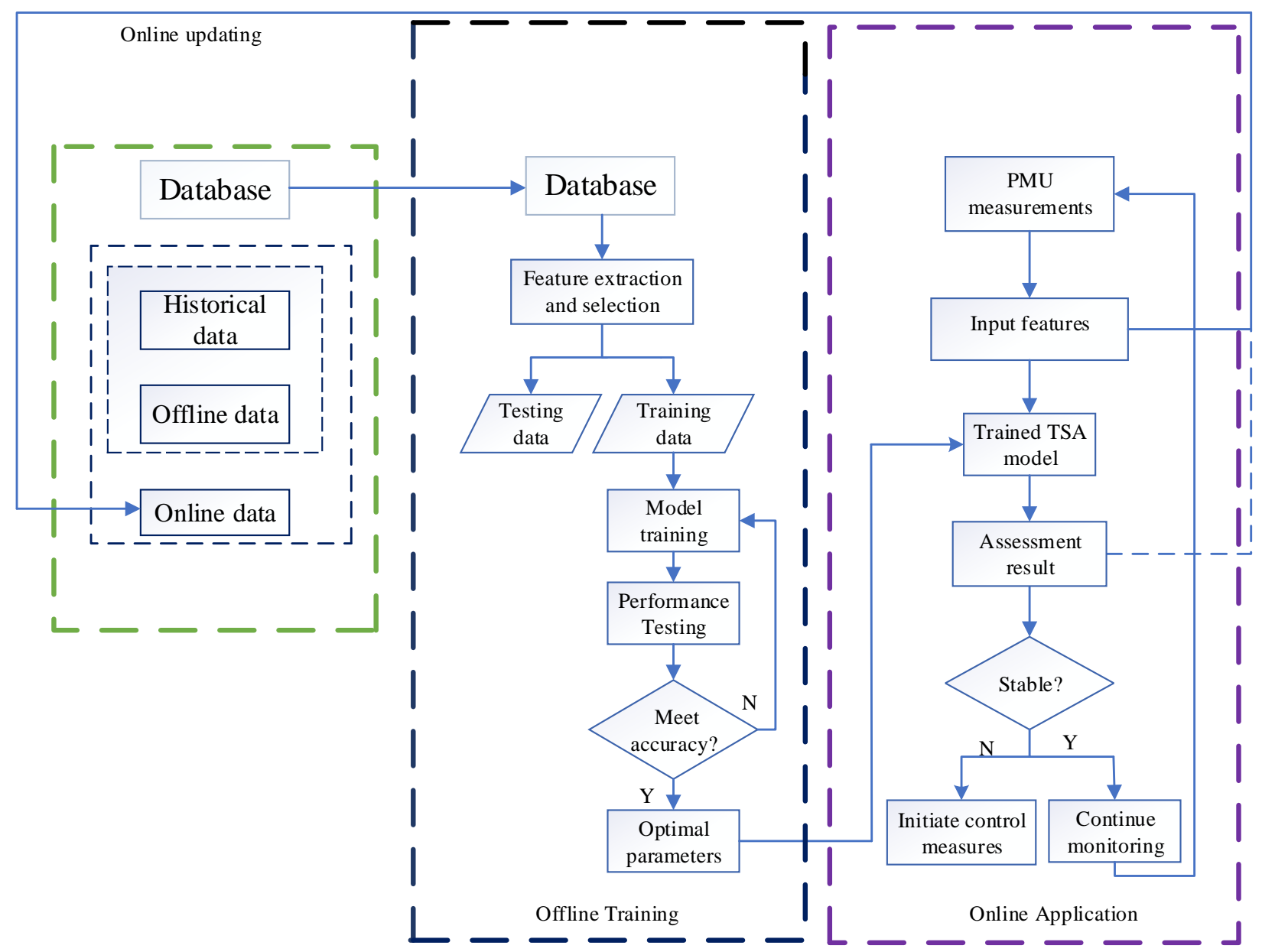

Figure 3. Flowchart of a typical data-driven transient stability assessment method.

\section{Future Challenges and Prospects}

\subsection{Impact of Renewable Energy Integration}

At present, today's power system is in a transitional stage toward a hybrid power system with high penetration of renewables. In recent years, the proportion of renewable energy resources in power systems was increasing [52]. As a result, the dynamic characteristics of power systems are becoming more and more complex. As an important form of renewable energy integration, microgrids were vigorously promoted in power systems [53]. Taking into account the uncertainties of load and renewable power generation, a chance constrained programming based optimal dispatch model of isolated microgrids with energy storage is proposed in reference [54]. However, as a kind of clean energy, renewable energy has inherent uncertainties [55,56], which will affect the secure operation of power systems. With the grid connection of large wind farms, the power flow of the power system will also change and interact with synchronous generators to affect the small signal angle stability of the power system [57]. Reference [58] considers the impact of different types and capacities of wind power generators on the power grid, and then investigates the influence of large-scale renewable integration on the transient stability of a power system. Reference [59] studies the equivalent modelling of hybrid renewable energy source plants for TSA. A probabilistic TSA method is proposed for power systems with renewables in reference [60].

The above comprehensive analysis shows that power systems are becoming increasingly complex due to the integration of renewables. Therefore, the stability analysis of power grid operation gradually shifted to online analysis, which is an inevitable result of the development of power grid systems. However, there are still many challenges and 
difficulties in the analysis process. Therefore, the development process of analysis methods is relatively slow. The relevant theories for system large interference problem analysis are mature, and there are relatively many types of software that can be used for calculation. However, the application of software and the limited control of stable operation of the power grid is relatively difficult, and in-depth exploration by relevant industry personnel is required.

\subsection{Stability Assessment of AC/DC Systems with VSC-HVDC}

Voltage source converter-based high-voltage direct current transmission (VSC-HVDC) is a new type of direct current transmission technology. Wind farms are connected to the grid through the VSC-HVDC system, and the voltage stability, power quality, and penetration power can be significantly improved. Especially in some areas where the development of wind power is encountering difficulties, the use of VSC-HVDC provides an effective way to address the technical problems of long-distance and large-capacity wind power transmission. However, when the voltage drops, the active power sent by a high-voltage direct current (HVDC) converter station is greatly reduced, which will cause the power imbalance between the receiving and sending ends of the converter station [61]. In some severe cases, the devices will be damaged or even the HVDC lines will be tripped, leading to the system instability and the failure of low voltage ride-through (LVRT). Therefore, how to assess the stability of AC/DC systems with VSC-HVDC has become a hot topic in the field of electrical engineering.

As a type of direct current transmission technology, voltage source converter based high voltage direct current transmission (VSC-HVDC) has received extensive attention from researchers due to its flexible and fast adjustment capabilities. Reference [62] proposes a two-stage solution method combining multiobjective optimization and decision support by using the nondominated sorting genetic algorithm II (NSGA-II). Reference [63] proposes a two-stage AC/DC system multi-objective optimal power flow (MOPF) method that integrates decision analysis into the optimization process. Reference [64] presents a controlled islanding model for AC/DC systems with VSC-HVDC to minimize the source-load imbalance by using semi-supervised spectral clustering, which uses VSC-HVDC links for power exchanges between islands. Reference [65] puts forward a black-start strategy based on VSC-HVDC for passive networks and carries out a number of simulation tests. The test results shows that VSC-HVDC can improve the system stability during the recovery process and shorten the system recovery time.

\subsection{Stability Assessment Considering Network Topology Changes}

Deep neural networks completely changed machine learning tasks. Although convolution neural networks are widely used, they have limitations in processing non-Euclidean spatial data. Graph neural network plays an important role in the application of nonEuclidean data in deep learning, especially the use of graph structures that can be explained on traditional Bayesian causal networks. It is of great significance to define the inferable and causal interpretable problems of deep neural network relationships. Therefore, how to use deep learning technology to analyze and reason about graph structure data has attracted widespread attention from scholars.

A large number of existing studies showed that transient instability of power systems exhibits certain spatial distribution characteristics. A TSA approach based on ensemble learning and kernel regression was presented taking into account topology changes in reference [37]. An energy margin analytical sensitivity method is developed for TSA of power systems considering topology changes in [66]. A TSA method based on ANN is presented with consideration of topology changes in [67]. Reference [68] verifies the influence of topology on power system transient and frequency stability, by studying the four network topologies: random graph, small-world graph, nested small-world graph, and lattice graph. Based on a message transfer graph neural network, a fast transient stability assessment method based on steady-state data is proposed for power systems 
in reference [69]. In this method, a TSA model that can describe power system topology changes can be trained by using graph data processing and topological modeling.

\subsection{Limitations in Applications and Prospects}

Currently, data-driven transient stability assessment methods face some challenges. First, it is tough and expensive to obtain large-scale, balanced data with accurate labels in real-world applications [70,71]. Then, existing data-driven TSA methods act as a black box with poor interpretability [72,73], which also limits their application in actual power systems. Finally, most of data-driven TSA methods generally lack the adaptability to topological changes.

At the same time, some emerging techniques are beneficial for developing advanced data-driven TSA methods. Firstly, data augmentation-based deep generative learning is a promising technique for addressing complex data analysis issues such as class imbalance and missing data [74,75]. Secondly, cutting-edge artificial intelligence techniques are helpful to build a powerful TSA model. For example, use of automated reinforcement learning can automatically determine the optimal model parameters of an assessment model [76]. It is also an interesting topic to balance accuracy and response speed by using multiobjective optimization $[77,78]$. Thirdly, the rapid improvement of software and hardware technology provides powerful computing power for data-driven TSA methods [79-81].

\section{Conclusions}

With the integration of power electronic equipment and renewable energy resources, today's power systems are evolving towards a new generation of power systems with high-penetration renewable energy and power electronics. These changes pose huge challenges for transient stability assessment of power systems. Unlike traditional time domain simulation and energy function methods, data-driven TSA methods establish the relationship between the system operational parameters and the stability status, and then directly determine the stability results, which do not require the physical model and parameter information of a power system.

Fast and accurate transient stability assessment plays a crucial role in ensuring the secure and stable operation of power systems. This review article summarizes datadriven transient stability assessment methods from four aspects, i.e., feature extraction and selection, model construction, online learning, and rule extraction. Then, it discusses main challenges and the future development direction in the field. This review will be helpful for relevant researchers to better understand the research status, key technologies, and existing challenges in the area of data-driven transient stability assessment of power systems.

Author Contributions: The paper was a collaborative effort among the authors. All authors have read and agreed to the published version of the manuscript.

Funding: This research was funded by the Natural Science Foundation of Jilin Province, China grant number YDZJ202101ZYTS149.

Institutional Review Board Statement: Not applicable.

Informed Consent Statement: Not applicable.

Acknowledgments: This work is partly supported by the Natural Science Foundation of Jilin Province, China under Grant No. YDZJ202101ZYTS149.

Conflicts of Interest: The authors declare no conflict of interest.

\section{References}

1. Kundur, P.; Paserba, J.; Ajjarapu, V.; Andersson, G.; Bose, A.; Canizares, C.; Hatziargyriou, N.; Hill, D.; Stankovic, A.; Taylor, C.; et al. Definition and classification of power system stability. IEEE Trans. Power Syst. 2004, 19, 1387-1401.

2. Zadkhast, S.; Jatskevich, J.; Vaahedi, E. A multi-decomposition approach for accelerated time-domain simulation of transient stability problems. IEEE Trans. Power Syst. 2014, 30, 2301-2311. [CrossRef] 
3. Chiang, H.D. Direct Methods for Stability Analysis of Electric Power Systems: Theoretical Foundation, BCU Methodologies, and Applications; John Wiley \& Sons: Hoboken, NJ, USA, 2011.

4. Wehenkel, L.; Van Cutsem, T.; Ribbens-Pavella, M. An artificial intelligence framework for online transient stability assessment of power systems. IEEE Trans. Power Syst. 1989, 4, 789-800. [CrossRef]

5. Deepa, N.; Prabadevi, B.; Maddikunta, P.K.; Gadekallu, T.R.; Baker, T.; Khan, M.A.; Tariq, U. An AI-based intelligent system for healthcare analysis using ridge-adaline stochastic gradient descent classifier. J. Supercomput. 2021, 77, 1998-2017. [CrossRef]

6. Liu, Y.; Sun, K.; Yao, R.; Wang, B. Power system time domain simulation using a differential transformation method. IEEE Trans. Power Syst. 2019, 34, 3739-3748. [CrossRef]

7. Khaitan, S.K.; McCalley, J.D.; Chen, Q. Multifrontal solver for online power system time-domain simulation. IEEE Trans. Power Syst. 2008, 23, 1727-1737. [CrossRef]

8. Chen, Y.; Shen, C.; Wang, J. Distributed transient stability simulation of power systems based on a Jacobian-free Newton-GMRES method. IEEE Trans. Power Syst. 2009, 24, 146-156. [CrossRef]

9. Rashidi, M.; Farjah, E. Lyapunov exponent-based optimal PMU placement approach with application to transient stability assessment. IET Sci. Meas. Technol. 2016, 10, 492-497. [CrossRef]

10. Jafarzadeh, S.; Genc, I.; Nehorai, A. Real-time transient stability prediction and coherency identification in power systems using Koopman mode analysis. Electr. Power Syst. Res. 2021, 201, 107565. [CrossRef]

11. Zhang, Y.; Wehenkel, L.; Rousseaux, P.; Pavella, M. SIME: A hybrid approach to fast transient stability assessment and contingency selection. Int. J. Electr. Power Energy Syst. 1997, 19, 195-208. [CrossRef]

12. Ernst, D.; Ruiz-Vega, D.; Pavella, M.; Hirsch, P.; Sobajic, D. A unified approach to transient stability contingency filtering, ranking and assessment. IEEE Trans. Power Syst. 2001, 16, 435-443. [CrossRef]

13. Huang, T.; Wang, J. A practical method of transient stability analysis of stochastic power systems based on EEAC. Int. J. Electr. Power Energy Syst. 2019, 107, 167-176. [CrossRef]

14. Li, M.; Pal, A.; Phadke, A.G.; Thorp, J.S. Transient stability prediction based on apparent impedance trajectory recorded by PMUs. Int. J. Electr. Power Energy Syst. 2014, 54, 498-504. [CrossRef]

15. Farantatos, E.; Huang, R.; Cokkinides, G.J.; Meliopoulos, A.P. A predictive generator out-of-step protection and transient stability monitoring scheme enabled by a distributed dynamic state estimator. IEEE Trans. Power Deliv. 2015, 31, 1826-1835. [CrossRef]

16. Sawhney, H.; Jeyasurya, B. A feed-forward artificial neural network with enhanced feature selection for power system tran-sient stability assessment. Electr. Power Syst. Res. 2006, 76, 1047-1054. [CrossRef]

17. Ye, S.; Wang, X.; Liu, Z.; Qian, Q. Dual-stage feature selection for transient stability assessment based on support vector machine. Proc. CSEE 2010, 30, 28-34.

18. Wahab, N.I.A.; Mohamed, A.; Al Dabbagh, M. Transient stability assessment of a large actual power system using least squares support vector machine with enhanced feature selection. In Proceedings of the 2008 Australasian Universities Power Engineering Conference, Sydney, Australia, 14-17 December 2008; pp. 1-6.

19. Gu, X.; Li, Y. Feature selection for transient stability assessment based on improved maximal relevance and minimal redundancy criterion. Proc. CSEE 2013, 33, 179-186.

20. Zhang, C.; Li, Y.; Yu, Z.; Tian, F. Feature selection of power system transient stability assessment based on random forest and recursive feature elimination. In Proceedings of the 2016 IEEE PES Asia-Pacific Power and Energy Engineering Conference (APPEEC), Xi'an China, 25-28 October 2016; pp. 1264-1268.

21. Jensen, C.A.; El-Sharkawi, M.A.; Marks, R.J. Power system security assessment using neural networks: Feature selection using Fisher discrimination. IEEE Trans. Power Syst. 2001, 16, 757-763. [CrossRef]

22. Tan, B.; Yang, J.; Zhou, T.; Xiao, Y.; Zhou, Q. A Novel Temporal Feature Selection for Time-Adaptive Transient Stability Assessment. In Proceedings of the 2019 IEEE PES Innovative Smart Grid Technologies Europe (ISGT-Europe), Bucharest, Romania, 29 September-2 October 2019; pp. 1-5.

23. Wahab, N.I.A.; Mohamed, A. Transient stability assessment of a large actual power system using a probabilistic neural network with enhanced feature selection and extraction. In Proceedings of the 2009 International Conference on Electrical Engineering and Informatics, Selangor, Malaysia, 5-7 August 2009; Volume 2, pp. 519-524.

24. Peng, H.; Long, F.; Ding, C. Feature selection based on mutual information criteria of max-dependency, max-relevance, and min-redundancy. IEEE Trans. Pattern Anal. Mach. Intell. 2005, 27, 1226-1238. [CrossRef]

25. Li, Y.; Yang, Z. Application of EOS-ELM with binary Jaya-based feature selection to real-time transient stability assessment using PMU data. IEEE Access 2017, 5, 23092-23101. [CrossRef]

26. Sobajic, D.J.; Pao, Y.H. Artificial neural-net based dynamic security assessment for electric power systems. IEEE Trans. Power Syst. 1989, 4, 220-228. [CrossRef]

27. Yu, J.J.Q.; Hill, D.J.; Lam, A.Y.S.; Gu, J.; Li, V.O.K. Intelligent time-adaptive transient stability assessment system. IEEE Trans. Power Syst. 2017, 33, 1049-1058. [CrossRef]

28. Luo, Y.; Lu, C.; Zhu, L.; Song, J. Data-driven short-term voltage stability assessment based on spatial-temporal graph convolutional network. Int. J. Electr. Power Energy Syst. 2021, 130, 106753. [CrossRef]

29. Shi, Z.; Yao, W.; Zeng, L.; Wen, J.; Fang, J.; Ai, X.; Wen, J. Convolutional neural network-based power system transient stability assessment and instability mode prediction. Appl. Energy 2020, 263, 114586. [CrossRef] 
30. Huang, J.; Guan, L.; Su, Y.; Yao, H.; Guo, M.; Zhong, Z. Recurrent graph convolutional network-based multi-task transient stability assessment framework in power system. IEEE Access 2020, 8, 93283-93296. [CrossRef]

31. Moulin, L.; Da Silva, A.; El-Sharkawi, M.; MarksII, R. Support vector machines for transient stability analysis of large-scale power systems. IEEE Trans. Power Syst. 2004, 19, 818-825. [CrossRef]

32. Hu, W.; Lu, Z.; Wu, S.; Zhang, W.; Dong, Y.; Yu, R.; Liu, B. Real-time transient stability assessment in power system based on improved SVM. J. Mod. Power Syst. Clean Energy 2019, 7, 26-37. [CrossRef]

33. Wang, B.; Fang, B.; Wang, Y.; Liu, H.; Liu, Y. Power system transient stability assessment based on big data and the core vector machine. IEEE Trans. Smart Grid 2016, 7, 2561-2570. [CrossRef]

34. Wang, Q.; Pang, C.; Alnami, H. Transient stability assessment of a power system using multi-layer SVM method. In Proceedings of the 2021 IEEE Texas Power and Energy Conference (TPEC), College Station, TX, USA, 4-5 February 2021; pp. 1-5.

35. Sarajcev, P.; Kunac, A.; Petrovic, G.; Despalatovic, M. Power system transient stability assessment using stacked autoencoder and voting ensemble. Energies 2021, 14, 3148. [CrossRef]

36. Li, Y.; Li, G.; Wang, Z.; Han, Z.; Bai, X. A multifeature fusion approach for power system transient stability assessment using PMU data. Math. Probl. Eng. 2015, 2015, 786396. [CrossRef]

37. Liu, X.; Zhang, X.; Chen, L.; Xu, F.; Feng, C. Data-driven transient stability assessment model considering network topology changes via mahalanobis kernel regression and ensemble learning. J. Mod. Power Syst. Clean Energy 2020, 8, 1080-1091. [CrossRef]

38. He, M.; Zhang, J.; Vittal, V. Robust online dynamic security assessment using adaptive ensemble decision-tree learning. IEEE Trans. Power Syst. 2013, 28, 4089-4098. [CrossRef]

39. Zhu, Q.; Dang, J.; Chen, J.; Zhu, L.; Shi, D.; Bai, X.; Duan, X.; Liu, Y. A method for power system transient stability assessment based on deep belief networks. Proc. CSEE 2018, 38, 735-743.

40. Yin, X.; Liu, Y. Deep learning based feature reduction for power system transient stability assessment. In Proceedings of the TENCON 2018: 2018 IEEE Region 10 Conference, Jeju Island, Korea, 28-31 October 2018; pp. 2308-2312.

41. Azman, S.K.; Isbeih, Y.J.; El Moursi, M.S.; Elbassioni, K. A unified online deep learning prediction model for small signal and transient stability. IEEE Trans. Power Syst. 2020, 35, 4585-4598. [CrossRef]

42. Zhang, M.; Li, J.; Li, Y.; Xu, R. Deep learning for short-term voltage stability assessment of power systems. IEEE Access 2021, 9 , 29711-29718. [CrossRef]

43. Li, Y.; Gu, X.P. Application of online SVR in very short-term load forecasting. Int. Rev. Electr. Eng. 2013, 8, 277-282.

44. Zhang, W.; Hu, W.; Min, Y.; Chen, L.; Zheng, L.; Liu, X. A novel stability classifier based on reformed support vector machines for online stability assessment. In Proceedings of the 2015 IEEE PES Asia-Pacific Power and Energy Engineering Conference (APPEEC), Brisbane, Australia, 15-18 November 2015; pp. 1-5.

45. Li, Y.; Gu, X. Power system transient stability assessment based on online sequential extreme learning machine. In Proceedings of the 2013 IEEE PES Asia-Pacific Power and Energy Engineering Conference (APPEEC), Hong Kong, China, 8-11 December 2013; pp. 1-4.

46. Zhu, L.; Hill, D.J.; Lu, C. Hierarchical deep learning machine for power system online transient stability prediction. IEEE Trans. Power Syst. 2019, 35, 2399-2411. [CrossRef]

47. Li, N.; Li, B.; Han, Y.; Gao, L. Dual cost-sensitivity factors-based power system transient stability assessment. IET Gener. Transm. Distrib. 2020, 14, 5858-5869.

48. Sun, H.; Wang, K.; Zhang, B.; Zhao, F. Rule extraction in transient stability study using linear decision trees. Proc. CSEE 2011, 31, 61-67.

49. Shi, F.; Zhang, L.; Hu, X. Power system transient stability rules extraction based on multi-attribute decision tree. Trans. China Electrotech. Soc. 2019, 34, 2364-2374.

50. Li, Y.; Li, G.; Wang, Z. Rule extraction based on extreme learning machine and an improved ant-miner algorithm for transient stability assessment. PLoS ONE 2015, 10, e0130814. [CrossRef] [PubMed]

51. Wang, T.W.; Guan, L. Power system stability assessment and rule extraction based on pattern discovery. Proc. CSEE 2007, 27, 25-31.

52. Li, Y.; Yang, Z.; Zhao, D.; Lei, H.; Cui, B.; Li, S. Incorporating energy storage and user experience in isolated microgrid dispatch using a multi-objective model. IET Renew. Power Gener. 2019, 13, 973-981. [CrossRef]

53. Li, Y.; Yang, Z.; Li, G.; Mu, Y.; Zhao, D.; Chen, C.; Shen, B. Optimal scheduling of isolated microgrid with an electric vehicle battery swapping station in multi-stakeholder scenarios: A bi-level programming approach via real-time pricing. Appl. Energy 2018, 232, 54-68. [CrossRef]

54. Li, Y.; Yang, Z.; Li, G.; Zhao, D.; Tian, W. Optimal scheduling of an isolated microgrid with battery storage considering load and renewable generation uncertainties. IEEE Trans. Ind. Electron. 2018, 66, 1565-1575. [CrossRef]

55. Li, Y.; Han, M.; Yang, Z.; Li, G. Coordinating flexible demand response and renewable uncertainties for scheduling of community integrated energy systems with an electric vehicle charging station: A bi-level approach. IEEE Trans. Sustain. Energy 2021, 12, 2321-2331. [CrossRef]

56. Li, Y.; Wang, C.; Li, G.; Chen, C. Optimal scheduling of integrated demand response-enabled integrated energy systems with uncertain renewable generations: A Stackelberg game approach. Energy Convers. Manag. 2021, 235, 113996. [CrossRef]

57. Du, W.; Bi, J.; Wang, T.; Wang, H. Impact of grid connection of large-scale wind farms on power system small-signal angular stability. CSEE J. Power Energy Syst. 2015, 1, 83-89. [CrossRef] 
58. Liu, M.; Sun, Z.; Liu, G.; Li, M.; Qiu, X. Study on the influence of large-scale wind power integration on transient stability of power system. In Proceedings of the 2019 IEEE 8th International Conference on Advanced Power System Automation and Protection (APAP), Xi'an, China, 21-24 October 2019; pp. 1156-1159.

59. Radovanovic, A.; Milanovic, J.V. Equivalent modelling of hybrid RES plant for power system transient stability studies. In IEEE Transactions on Power Systems; to be published; IEEE: Piscataway, NJ, USA, 2021. [CrossRef]

60. Papadopoulos, P.N.; Milanović, J.V. Probabilistic framework for transient stability assessment of power systems with high penetration of renewable generation. IEEE Trans. Power Syst. 2016, 32, 3078-3088. [CrossRef]

61. Feltes, C.; Wrede, H.; Koch, F.W.; Erlich, I. Enhanced fault ride-through method for wind farms connected to the grid through VSC-based HVDC transmission. IEEE Trans. Power Syst. 2009, 24, 1537-1546. [CrossRef]

62. Li, Y.; Li, Y.; Li, G. A two-stage multi-objective optimal power flow algorithm for hybrid AC/DC grids with VSC-HVDC. In Proceedings of the 2017 IEEE Power \& Energy Society General Meeting, Chicago, IL, USA, 16-20 July 2017; pp. 1-5.

63. Li, Y.; Li, Y.; Li, G.; Zhao, D.; Chen, C. Two-stage multi-objective OPF for AC/DC grids with VSC-HVDC: Incorporating decisions analysis into optimization process. Energy 2018, 147, 286-296. [CrossRef]

64. Li, Y.; Wu, S. Controlled islanding for a hybrid AC/DC grid with VSC-HVDC using semi-supervised spectral clustering. IEEE Access 2019, 7, 10478-10490. [CrossRef]

65. Feng, B.; Zhai, X.; Li, Y.; Wang, Z. Experimental study on black-start capability of VSC-HVDC for passive networks. In Proceedings of the 2016 IEEE PES Asia-Pacific Power and Energy Engineering Conference (APPEEC), Xi'an, China, 25-28 October 2016; pp. 2560-2563.

66. Chadalavada, V.; Vittai, V. Transient stability assessment for network topology changes: Application of energy margin analytical sensitivity. IEEE Trans. Power Syst. 1994, 9, 1658-1664. [CrossRef]

67. Hoballah, A.; Erlich, I. Transient stability assessment using ANN considering power system topology changes. In Proceedings of the 2009 15th International Conference on Intelligent System Applications to Power Systems, Curitiba, Brazil, 8-12 November 2009; pp. 1-6.

68. Ebrahimzadeh, F.; Adeen, M.; Milano, F. On the impact of topology on power system transient and frequency stability. In Proceedings of the 2019 IEEE International Conference on Environment and Electrical Engineering and 2019 IEEE Industrial and Commercial Power Systems Europe (EEEIC/I\&CPS Europe), Genova, Italy, 10-14 June 2019; pp. 1-5.

69. Wang, Z.; Zhou, Y.; Guo, Q.; Sun, H. Transient stability assessment of power system considering topological change: A message passing neural network-based approach. Proc. CSEE 2021, 41, 2341-2350.

70. Zhang, Y.; Li, T.; Na, G.; Li, G.; Li, Y. Optimized extreme learning machine for power system transient stability prediction using synchrophasors. Math. Probl. Eng. 2015, 2015, 529724. [CrossRef]

71. Gomez, F.R.; Rajapakse, A.D.; Annakkage, U.D.; Fernando, I.T. Support vector machine-based algorithm for post-fault transient stability status prediction using synchronized measurements. IEEE Trans. Power Syst. 2010, 26, 1474-1483. [CrossRef]

72. Wu, S.; Zheng, L.; Hu, W.; Yu, R.; Liu, B. Improved deep belief network and model interpretation method for power system transient stability assessment. J. Mod. Power Syst. Clean Energy 2019, 8, 27-37. [CrossRef]

73. Kamwa, I.; Samantaray, S.R.; Joós, G. On the accuracy versus transparency trade-off of data-mining models for fast-response PMU-based catastrophe predictors. IEEE Trans. Smart Grid 2011, 3, 152-161. [CrossRef]

74. Li, Y.; Li, J.; Wang, Y. Privacy-preserving spatiotemporal scenario generation of renewable energies: A federated deep generative learning approach. IEEE Trans. Ind. Inform. 2021. [CrossRef]

75. Ren, C.; Xu, Y. A fully data-driven method based on generative adversarial networks for power system dynamic security assessment with missing data. IEEE Trans. Power Syst. 2019, 34, 5044-5052. [CrossRef]

76. Li, Y.; Wang, R.; Yang, Z. Optimal scheduling of isolated microgrids using automated reinforcement learning-based multi-period forecasting. IEEE Trans. Sustain. Energy 2021. [CrossRef]

77. Ren, C.; Xu, Y.; Zhang, Y. Post-disturbance transient stability assessment of power systems towards optimal accuracy-speed tradeoff. Prot. Control. Mod. Power Syst. 2018, 3, 1-10. [CrossRef]

78. Li, Y.; Wang, J.; Zhao, D.; Li, G.; Chen, C. A two-stage approach for combined heat and power economic emission dispatch: Combining multi-objective optimization with integrated decision making. Energy 2018, 162, 237-254. [CrossRef]

79. Konstantelos, I.; Jamgotchian, G.; Tindemans, S.H.; Duchesne, P.; Cole, S.; Merckx, C.; Strbac, G.; Panciatici, P. Implementation of a massively parallel dynamic security assessment platform for large-scale grids. IEEE Trans. Smart Grid 2016, 8, 1417-1426. [CrossRef]

80. Suvorov, A.A.; Diab, A.A.Z.; Gusev, A.S.; Andreev, M.V.; Ruban, N.Y.; Askarov, A.B.; Ufa, R.A.; Razzhivin, I.A.; Kievets, A.V.; Bay, Y.D.; et al. Comprehensive validation of transient stability calculations in electric power systems and hardware-software tool for its implementation. IEEE Access 2020, 8, 136071-136091. [CrossRef]

81. Ruban, N.; Suvorov, A.; Andreev, M.; Ufa, R.; Askarov, A.; Gusev, A.; Bhalja, B.R. Software and hardware decision support system for operators of electrical power systems. IEEE Trans. Power Syst. 2021, 36, 3840-3848. [CrossRef] 